\title{
New Hybrid Control for Wide Input Full-bridge LLC Resonant DC/DC Converter
}

\author{
Yudi, Xiao; Xingkui, Mao; Zhang, Zhe; You, Shi
}

Published in:

Proceedings of 3rd International Conference on Intelligent Green Building and Smart Grid

Link to article, DOI:

10.1109/IGBSG.2018.8393556

Publication date:

2018

Document Version

Peer reviewed version

Link back to DTU Orbit

Citation (APA):

Yudi, X., Xingkui, M., Zhang, Z., \& You, S. (2018). New Hybrid Control for Wide Input Full-bridge LLC Resonant DC/DC Converter. In Proceedings of 3rd International Conference on Intelligent Green Building and Smart Grid IEEE. https://doi.org/10.1109/IGBSG.2018.8393556

\section{General rights}

Copyright and moral rights for the publications made accessible in the public portal are retained by the authors and/or other copyright owners and it is a condition of accessing publications that users recognise and abide by the legal requirements associated with these rights.

- Users may download and print one copy of any publication from the public portal for the purpose of private study or research.

- You may not further distribute the material or use it for any profit-making activity or commercial gain

- You may freely distribute the URL identifying the publication in the public portal 


\section{New Hybrid Control for Wide Input Full-bridge}

\section{LLC Resonant DC/DC Converter}

\author{
Xiao Yudi, *Mao Xingkui \\ College of Electrical Engineering and Automation \\ Fuzhou University \\ Fuzhou, China \\ Contact Email: mxk782@163.com
}

\author{
Zhang Zhe, You Shi \\ Department of Electrical Engineering \\ Technical University of Denmark \\ Kgs. Lyngby, Denmark
}

\begin{abstract}
In order to achieve low switching frequency range and high efficiency for a wide-input LLC resonant converter, a new hybrid control combining pulse-frequency modulation (PFM) and phase-shift pulse-width modulation (PS-PWM) is proposed. In the new control, the LLC converter has two operation modes, i.e PFM and PFM+PS-PWM. The new control scheme and operation principle is analyzed deeply, and then efficiency optimization can be carried out by the proposed design procedure for the resonant tank of LLC converter. Finally, a prototype is developed with input voltage range from $22 \mathrm{~V}$ to $45 \mathrm{~V}$, and rated power of $250 \mathrm{~W}$ and output voltage of $380 \mathrm{~V}$. The experiment shows that the peak efficiency of $L L C$ converter reaches to $96.2 \%$, and verifies the proposed control scheme, design.
\end{abstract}

Keywords - LLC resonant DC/DC converter, phase-shift PWM, PFM, new energy power generations.

\section{INTRODUCTION}

Wide input DC/DC converters have large applications, especially in new energy power generations, such as photovoltaics, wind, fuel cell etc[1-4]. LLC resonant DC/DC converter can achieve Zero voltage switching (ZVS) for the primary side switches and zero current switching (ZCS) for the secondary side diodes by resonance existing in the resonant tank, and can be used as boost power stage in the new energy power generation. With traditional PFM control shown as Control I in Fig.1-(b), power can be converted efficiently under narrow-range input voltage, where the voltage gain is only regulated with fs. But when using traditional PFM control for wide input voltage, great challenges in magnetic components, system stability, and system control will occur because of the wide-range switching frequency resulted from a wide input voltage and wide load variation. References [2, 5-10] proposed some topologies, control schemes and design for wide-input voltage LLC converters. By using hybrid control shown as Control II in Fig.1-(b), efficient power conversion can be realized for wide input voltage [10]. However, the efficiency will decrease under PS-PWM at high input voltage due to the large $\mathrm{D}$ which tending to result in the increases of internal circumfluent current loss. In order to overcome the drawbacks, a new hybrid control is proposed for wide-input LLC converters. And the related operation principle, digital control implementation, and efficiency optimization will be analysed deeply.

\section{NEW HYBRID CONTROL}

\section{A. New Hybrid Control and Operation Principle}

The driver signal is shown as Fig.1-(b) for the full-bridge LLC resonant converter of Fig.1-(a). A new hybrid control is proposed as Control III in Fig.1-(c) with vertical and horizontal

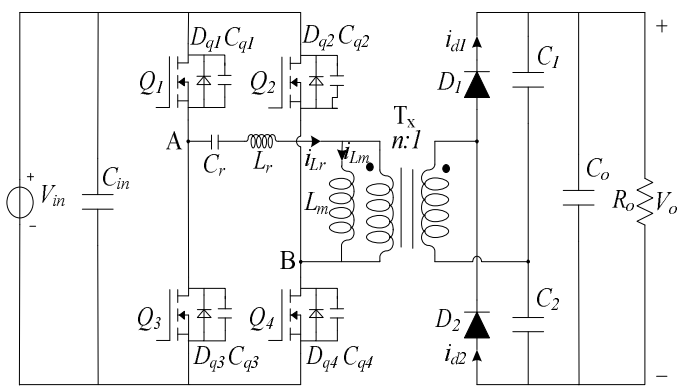

(a) A full-bridge LLC resonant converter

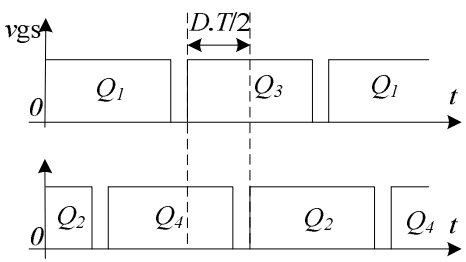

(b) Driving signal of $Q 1-Q 4$
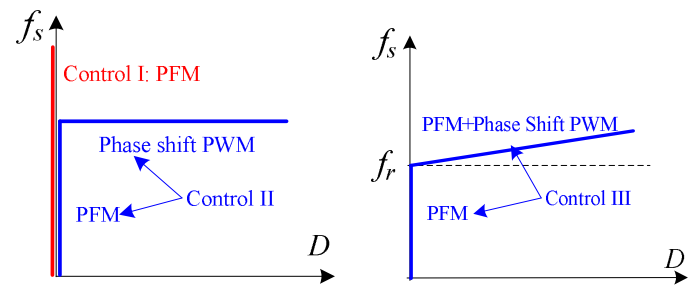

(c) Switching frequency $f_{s}$ vs. phase-shift duty cycle $D$

Fig.1 Control scheme for full-bridge LLC resonant converter 
axis representing the switching frequency fs, and the phaseshift duty cycle $D$ respectively. The previous control schemes are also shown as Control I, and Control II for comparing. In the new Control III, there are two control modes. One is socalled PFM control mode when the converter $f_{s} \leq f_{r}\left(f_{r}\right.$ is the resonant frequency of the LLC converter resonant tank), the other is control mode of combining PFM and PS-PWM (PFM+PS-PWM) when $f_{s}>f_{r}$. Here the $f_{r}$ is designed as a transition frequency of the two control modes, and the converter $f_{s}$ is designed to be equal to $f_{r}$ at nominal input voltage and output load working condition. Because PFM is also introduced to combine PS-PWM for regulation, $D$ will be reduced. Then not only the $f_{s}$ range is limited effectively in favor of magnetic component design, system control, etc., but also the circumfluent current loss can be decreased because of small $D$.

When the converter operates with PFM control mode, it has the same analysis and a voltage gain $M$ with the converter controlled by the traditional PFM control shown as Control I. When the converter operates with PFM+PS-PWM control mode, its key waveforms are shown in Fig.2, and its $M$ can be described by (1) considering relatively small $D$ for simplifying the analysis. Where $D^{\prime}=1-D, k=$ magnetizing inductance $L_{m} / L_{r}$, $Q$ is the quality factor of the resonant tank. The $M$ acts as the function of fs and $D . k$ and $Q$ are fixed with the constant parameters of the resonant tank.

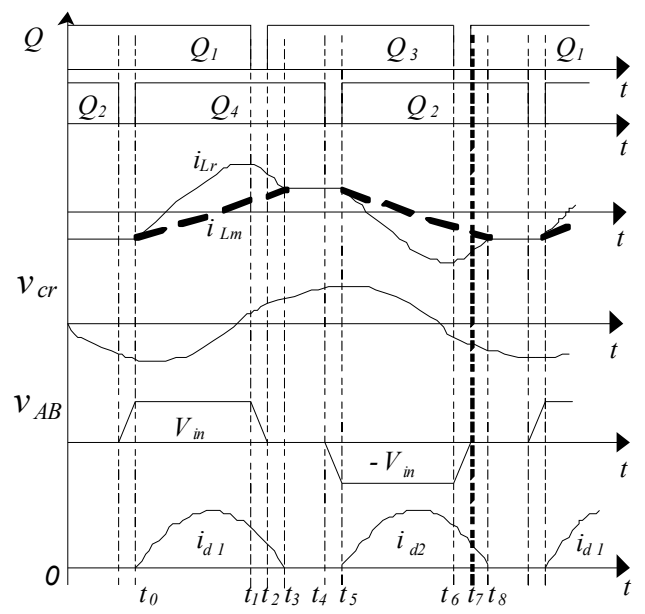

Fig. 2 Key waveform under PFM+PS-PWM control mode

$$
M\left(f_{S}, D, k, Q\right)=\sin \frac{D^{\prime} \pi}{2} \frac{1}{\sqrt{\left[\left(1-\frac{1}{f_{s}^{2}}\right) \frac{1}{k}+1\right]^{2}+\left[\left(f_{s}-\frac{1}{f_{s}}\right) \cdot \frac{2}{1-\cos \left(D^{\prime} \pi\right)} Q\right]^{2}}}
$$

\section{B. Hybrid Control Implementation and Its Digitalization}

In the new hybrid control, the PFM control mode can be realized the same as that of traditional PFM control. But there exists a variety of combinations $f_{s}$ and $D$ under PSPWM+PFM mode for a specific $M$. The combination guideline can be analyzed based on Equation (1).
Normalized $f\left(f=f_{s} / f_{r}\right) v s . Q$ and $D$ at different $M$ are shown in Fig.3. It shows that,

1. $\Delta f 1<\Delta f 2$, which means the range of $f_{s}$ is limited more effectively at small $M$, i.e. under high input voltage.

2. The effect of PS-PWM on limiting $f_{s}$ will be weakened with the increases of $Q$, i.e. under heavy loads.

So, the guideline is that introducing large weight for PSPWM under high input voltage or light load, and large weight for PFM under relative high input voltage or heavy load. Large weight for PS-PWM means that the converter is regulated mainly by PS-PWM and mainly by PFM vice versa. This combination can achieve a good trade-off range limitation of between $f_{S}$ and $D$. The hybrid control can be easily realized by digital control, and the associated digital program flowchart is given in Fig.4.

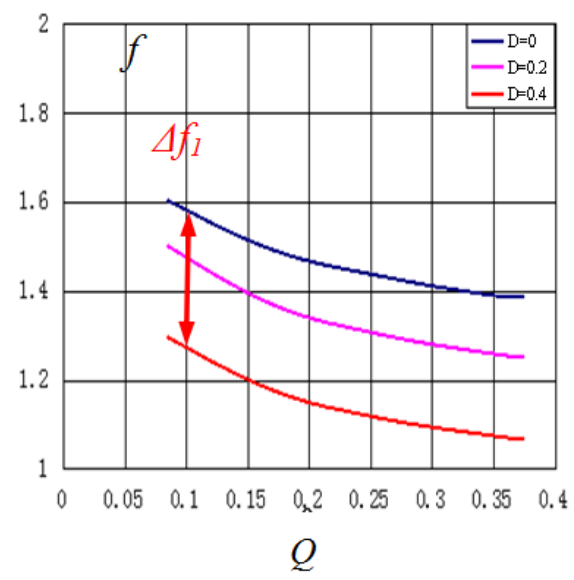

(a) $M=0.8$

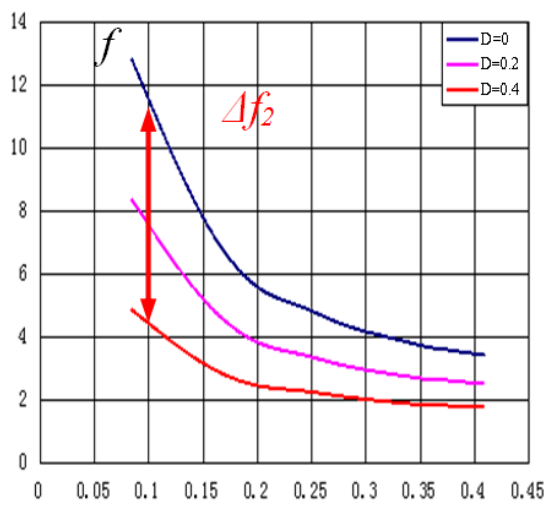

Q

(b) $M=0.55$

Fig.3. $f$ vs. $Q$ and $D @ k=3.7$ under PFM+PS-PWM mode 


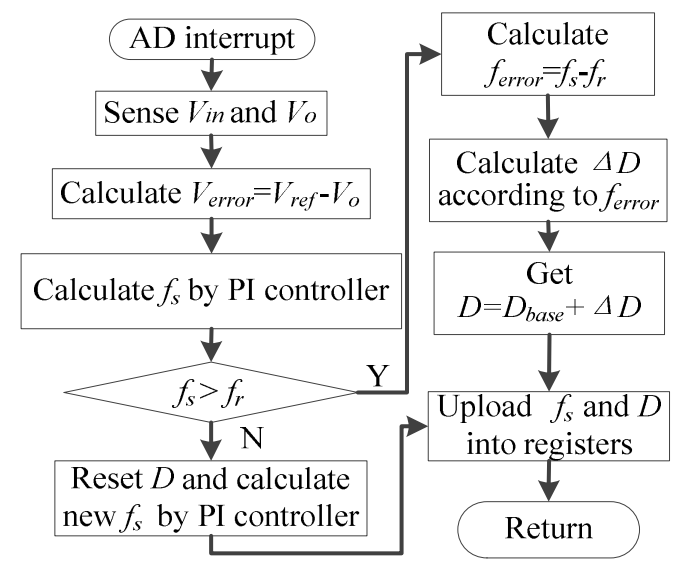

Fig.4. Program flowchart of hybrid control

\section{DESIGN OF KEY PARAMETERS}

The resonant tank design of the LLC resonant converter has impacts on voltage gain $M$, switches' losses, and magnetic losses. Minimizing loss is the target of designing the resonant tank by analyzing the impact of resonant tank parameters $k, Q$ on $M$ and losses. And RMS current $I_{Q r m s}$, turn-off current $i_{Q}$ off is used to evaluate switches conduction and turn-off loss respectively. By a deep analysis, only impacts of $k, Q$ on $M$ and losses under PFM control mode is considered in the design $k$ and $Q$. Moreover, the magnetizing current decreases effectively with larger $L_{m}$, which is proportional to the product of $k$ and $Q$. So, design rule of the resonant tank is concluded to maximize the product of $k$ and $Q$ under satisfying voltage gain.

Then, requirements in the design the LLC converter is described as equation (2) and (3),

1. Requirement on $M$ :

$$
M\left(f_{\min }\right) \geq M_{\max }
$$

$M\left(f_{\min }\right)$ is $M$ at the minimum frequency $f_{\min }$, and $M_{\max }$ is the maximum $M$ for the full input and load.

2. Input impedance of the converter need to be inductive for primary side switches under ZVS operation.

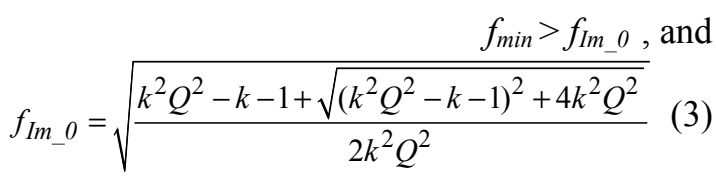

$k$ and $Q$ of overlapped parts in Fig.5 satisfies both Inequality (2) and (3). Then finding $k$ and $Q$ to maximize the product of $k$ and $Q$ can achieve optimal design.

\section{EXPERIMENTAL RESULTS}

Based on the design procedure, key parameters of the prototype used as boost power stage of PV micro-inverter is designed as follows, Input: $22-45 \mathrm{~V} /$ nominal $31 \mathrm{~V}$; output: $380 \mathrm{~V} /$ rated power $250 \mathrm{~W} ; f_{s}: 80 \mathrm{k}-120 \mathrm{kHz}$, and $f_{r}=100 \mathrm{kHz}$; parameters of resonant tank: $k=3, Q=0.49, L_{r}=4.9 \mathrm{uH}$, $C_{r}=0.52 \mathrm{uF}, L_{m}=4.9 \mathrm{mH}$, turns ratio of Tx: 8:48. The key

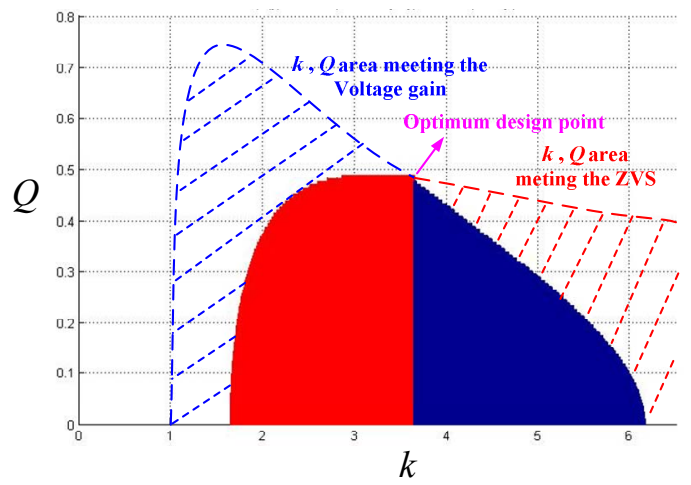

Fig.5. $k, Q$ area meeting the voltage gain and ZVS

waveforms of the converter vs. input voltage are given in Fig.6. The experiment shows that the converter operates under PFM control mode when $f_{s}<f_{r}$, while operates at PFM+PS-PWM control mode, and $f_{s}=f_{r}$ at nominal input $31 \mathrm{~V}$. Comparing with $f_{s}=120 \mathrm{kHz}$ and $D=0.17$ at $\mathrm{V}_{\text {in }}=39 \mathrm{~V}$ in Fig.6-(c), $f_{s}$ keeps $120 \mathrm{kHz}, \mathrm{b} D=0.32$ at $\mathrm{V}_{\text {in }}=45 \mathrm{~V}$. The peak-efficiency reaches to $96.2 \%$. It should be noted that ZCS for the diodes, which is helpful to suppress voltage spikes, is also achieved even when $f_{s}>f_{r}$ because of hybrid control.
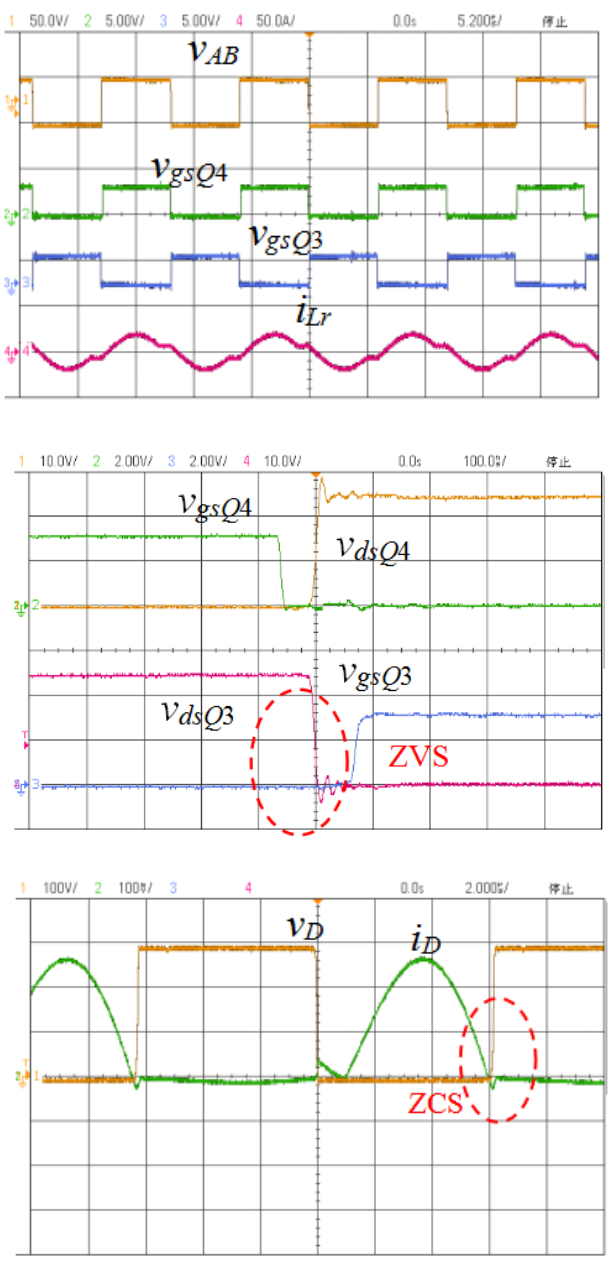

(a). $f s=80.7 \mathrm{kHz} @ V_{\text {in }}=25 \mathrm{~V}$, output power $P_{o}=250 \mathrm{~W}$ 

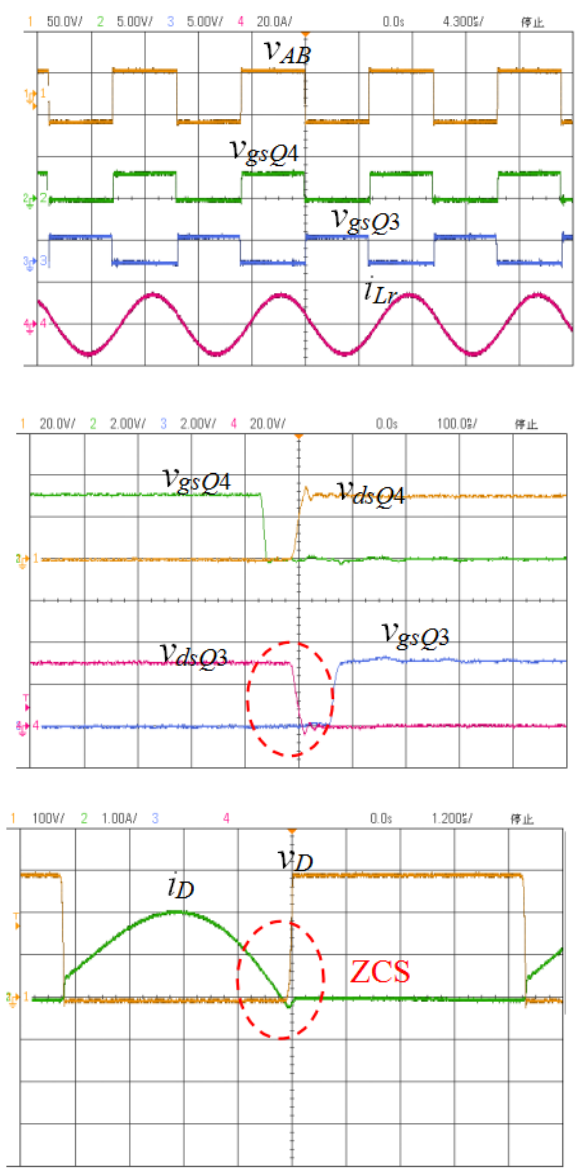

(b). $f_{s}=97.9 \mathrm{kHz}\left(\approx f_{r}=100 \mathrm{kHz}\right) @ V_{i n}=31 \mathrm{~V}$, output power $P_{o}=250 \mathrm{~W}$
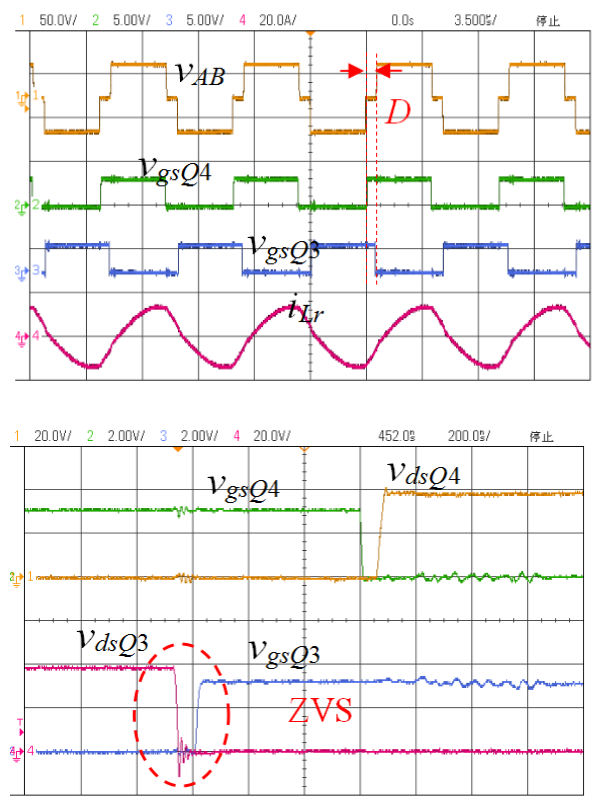

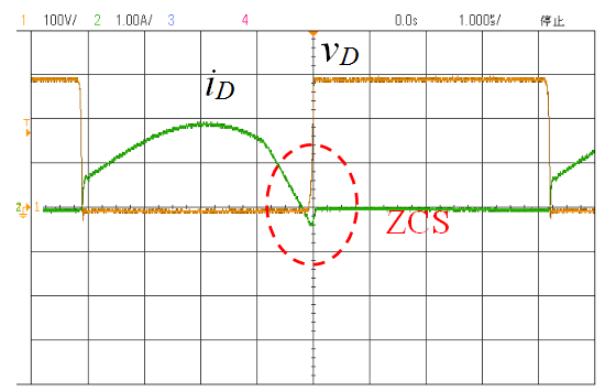

(c). $f_{s}=120 \mathrm{kHz}$ and $D=0.17 @ V_{\text {in }}=39 \mathrm{~V}, P_{o}=250 \mathrm{~W}$

Fig.6 Key waveform of full-bridge LLC converter vs. $V_{\text {in }}$

\section{CONCLUSIONS AND FUtURE WORK}

In the new hybrid control for a wide-input full-bridge LLC resonant DC/DC converter, the converter operates PFM mode when switching frequency is lower than the resonant frequency; otherwise, it operates with combining PFM and phase-shift PWM mode instead. So, not only switching frequency range is limited, but also circumfluent current loss is decreased due to the reductions of phase-shift duty cycle. Efficiency optimal design is implemented with the proposed design procedure for the resonant tank. Finally, the experiments verify the validity of the proposed scheme, design and control method.

\section{REFERENCES}

[1] Xinbo Ruan, Bin Li, "Zero-voltage and zero-current-switching PWM hybrid full-bridge three-level converter", IEEE Trans. on I.E, vol.52, no.1, pp.213-220, Feb.2005.

[2] Haibing $\mathrm{Hu}$, et al., "A modified high-efficiency LLC converter with two transformers for wide input-voltage range applications", IEEE Trans. on P.E, vol.28, no.4, pp.1946-1960, Apr. 2013.

[3] Wardah Inam, K. K. Afridi, David J. P., "High efficiency resonant DC/DC converter utilizing a resistance compression network", IEEE Trans. on P.E, vol.29, no.8, pp.4126- 4135, Aug.2014.

[4] Mao Xingkui, Huang Qisheng, Ke Qingbo, et al. "Grid-connected photovoltaic micro-inverter with new hybrid control LLC resonant converter". in IEEE 2016 IECON, 2016, pp. 2319-2324.

[5] B. Yang, "Topology investigation for front end DC/DC power conversion for distributed power system," Virginia Polytechnic Inst. State Univ., Ph.D. dissertation, 2003.

[6] Fang, Y., et al. "Design of high power density LLC resonant converter with extra wide input range", in IEEE 2007 Applied Power Electronics Conference and Exposition, 2007, pp. 976-981.

[7] R. Beiranvand, B. Rashidian, M. R. Zolghadri, and S. M. H. Alavi, "Optimizing the normalized dead-time and maximum switching frequency of a wide-adjustable-range LLC resonant converter," IEEE Trans. Power Electron., vol. 26, no. 2, pp. 462-472, Sep. 2011.

[8] I.-O. Lee, et al, "Analysis and design of a three-level LLC series resonant converter for high- and wide-input-voltage applications," IEEE Trans. P. E., vol. 27, no. 6, pp. 2966-2979, Jun. 2012.

[9] Jang, J., et al, "Dynamic analysis and control design of optocouplerisolated LLC series resonant converters with wide input and load variations", IET Power Electronics, vol. 5, no. 6, pp. 755-764, 2012.

[10] Li Ju, and RuanXinbo, "Hybrid control strategy of full bridge LLC converters", Trans. of China Electrotechnical Society, vol.28, no.4, pp.72-79, Apr. 2014. 